Section Editor

John J. Millichap, MD

Suresh Menon, MBBS, MD, DM

Mandar S. Jog, MD, FRCP

Correspondence to

Dr. Jog:

Mandar.Jog@lhsc.on.ca

Pearls \& Oy-sters:

\title{
Spinocerebellar ataxia type 3 presenting with cervical dystonia without ataxia
}

回的

PEARLS

1. There is marked heterogeneity in the clinical features of spinocerebellar ataxia type 3 (SCA3).

2. Similar to pure ataxia, pure focal dystonia (torticollis) can be the only presenting symptom of SCA3.

3. High level of vigilance to obtaining family history needs to be maintained in susceptible ethnic backgrounds.

4. Genetic testing should be pursued early in such a group despite atypical presentations.

\section{OY-STERS}

1. Focal dystonias such as cervical dystonia can be the sole presenting manifestation and can predate ataxia by many years.

2. An atypical presentation can lead to an incomplete exploration of family history even in susceptible populations of SCA3.

3. Family history of ataxia may not be easily revealed, especially in the immigrant population as other family members may not have dystonia, leading to a delay in diagnosis, as seen in these 2 cases.

CASE 1 A 43-year-old Portuguese woman from the Azores developed intermittent twisting of her head to the left side associated with some rotation and discomfort (video 1 on the Neurology ${ }^{\circledR}$ Web site at Neurology.org). Movements were relieved by maneuvers such as supporting the back of her neck with her hands. Medical history was positive for a cesarean section, uterine prolapse surgery, and thyroidectomy that was complicated by right vocal cord paralysis. There was no history of any medication use known to cause dystonia.

General physical examination was normal. On neurologic examination, extraocular movements and speech were normal. There was no nystagmus. Saccades and pursuit were normal. Motor examination showed lower limb physiologic hyperreflexia without spasticity, and power testing was normal. Sensory examination was normal. Finger chase, nose-finger and heel-shin slide were normal. Rapid alternating movements were normal, with no dysdiadochokinesia. Gait including tandem gait was intact. There was no sway on sitting. She was able to stand and hop on one foot. Dystonia examination showed pronounced antecollis associated with right tilt and twist and minimal sagittal and lateral shift and intermittent dystonic tremor. Sensory trick was seen in that touching the chin provided partial relief. There was fixed and painful dystonia with no change with posture. There was no dystonia of other body parts such as jaw or limbs. The detailed scoring of torticollis was as follows: (1) Toronto Western Spasmodic Torticollis Severity Scale (TWSTRS) Torticollis Severity Scale21; (2) TWSTRS Disability Scale-16; and (3) TWSTRS Pain Scale-11.5.

Botulinum toxin therapy produced either minimal relief or weakness and was abandoned after many attempts. Similarly, oral medication including levodopa did not produce any benefit.

Three years after her initial presentation, her examination showed hypometric saccades and reduced right arm swing and only mild impaired tandem gait. On initial and numerous subsequent visits, the patient did not reveal that there was a significant family history of late-onset ataxia in her sister, father, uncles, aunt, paternal grandmother, and several cousins living in the Azores (figure). None of them had torticollis and hence the patient did not consider the history of ataxia relevant. The family history was suggestive of an autosomal dominant pattern of inheritance (figure). Molecular genetic testing using PCR amplification was done to detect abnormal CAG trinucleotide repeat expansion within the ataxin 3 (ATXN3) gene. The pathologic allele had 70 CAG repeats and the normal allele had 23 CAG repeats, thus confirming the genetic diagnosis of SCA3.

A year later, she underwent globus pallidus interna deep brain stimulation, which did not improve her condition. Four years later, electrode repositioning was attempted without success and she developed worsening of her ataxia. The deep brain stimulation hardware was removed because of an infection.

Seventeen years after her initial presentation, she has worsening of neck and axial dystonia, limitation 


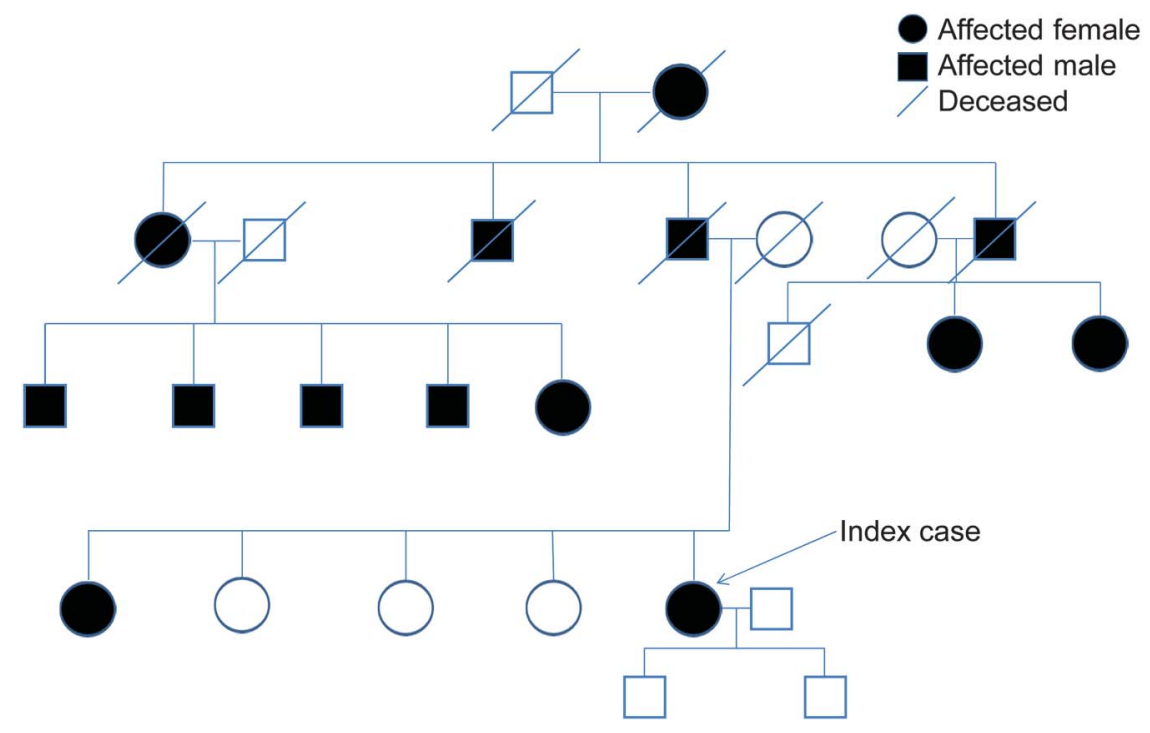

of vertical upgaze, kyphoscoliosis, bilateral upper limb tremors and cerebellar signs, and requires unilateral assistance for walking. Scoring on the Scale for the Assessment and Rating of Ataxia was 21.

CASE 2 A 22-year-old man presented to the clinic with a 4-year history of progressive twisting backward of the neck (video 2). There was no medical history of any neurologic or psychiatric illnesses and there was no exposure to drugs known to cause dystonic reactions. Neurologic examination was entirely normal except for the retrocollis. He was initially treated with botulinum toxin with good success and continued to have a fair response for several years. Subsequently, family history was obtained by the patient when he visited his family (who were of Portuguese descent) in Brazil. This was positive for a syndrome of ataxia and dysarthria.

Molecular genetic testing for SCA3 was ordered and was positive in the clinically certain range with the pathologic allele having 65 CAG trinucleotide repeats in the ATXN3 gene. The patient remained in the practice for approximately 3 years and then was lost to follow-up.

DISCUSSION Machado-Joseph disease, also known as SCA3, is the most common SCA worldwide and is described in families from different ethnic origins such as Portuguese, Spanish, Italian, Canadian, and others. SCA3 is inherited in an autosomal dominant fashion with considerable phenotypic variability.

A clinical diagnosis is usually suspected in patients presenting with cerebellar ataxia, pyramidal, extrapyramidal signs, and peripheral neuropathy. ${ }^{1}$ However, some clinical features may increase the diagnostic yield of SCA3, such as external progressive ophthalmoplegia (EPO), dystonia, action-dependent fasciculation-like movements of facial and lingual muscles, and bulging eyes. ${ }^{1}$ In general, focal or generalized forms of dystonia are uncommon in SCAs but if present usually accompany ataxia and are rarely seen in isolation.

We report 2 cases of genetically proven SCA3 who presented with cervical dystonia without ataxia posing a distinctive diagnostic pitfall. The diagnosis of SCAs based on clinical features alone is difficult, although some features seem more common in some SCA subtypes than in others. ${ }^{2}$ Coutinho and Andrade $^{3}$ have systemized the clinical presentation of SCA3 into 3 main types. Type 1 or Joseph type is characterized by ataxia, EPO, and pyramidal and extrapyramidal signs. It has an early age at onset (mean of 24.3 years) and rapid progression. ${ }^{3}$ Type 2 or Thomas type is characterized by ataxia and EPO with or without pyramidal and extrapyramidal signs, and peripheral neuropathy. ${ }^{3}$ It has an intermediate age at onset (mean of 40.5 years). ${ }^{3}$ Type 3 or Machado type is characterized by ataxia, EPO, and peripheral neuropathy with or without mild pyramidal and extrapyramidal signs with a later age at onset (mean of 46.8 years). ${ }^{3}$ A fourth type was suggested by some authors, which is characterized by mild ataxia, parkinsonism, and peripheral neuropathy. ${ }^{4}$

Sakai and Kawakami ${ }^{5}$ suggested a fifth type, without ataxia that was characterized by spastic paraplegia, which manifested in 2 siblings. Our 2 cases presented without ataxia and only dystonia but later went on to develop ataxia. SCA3 appears to be the most likely subtype of SCA having ataxia and dystonia. ${ }^{6}$ 
However, SCA3 is commonly associated with generalized or limb dystonia along with ataxia. ${ }^{7-9}$ There are also reported cases of focal dystonia including cervical dystonia and/or dystonic head tremor but as part of a generalized dystonia. ${ }^{7,8}$ More commonly, generalized forms of dystonia have been reported in many other SCA subtypes. ${ }^{10}$ Few reports found focal dystonia as a feature in certain SCAs, such as SCA2, SCA3, and other inherited ataxias. ${ }^{10}$ Cervical dystonia without clinical evidence of ataxia in SCA3 does not appear to be reported in literature.

These 2 cases highlight the marked clinical heterogeneity of SCA3, which makes the diagnosis of this disease extremely difficult without other clues to raise the suspicion of SCA3 or other SCAs. Our patients had cervical dystonia as their sole presenting manifestation of SCA3, which remained the only feature for many years. When SCA3 presents and remains as focal dystonia for years, the clinical diagnosis may not be suspected. In at-risk populations such as these patients with Portuguese descent, special vigilance may be necessary to make the correct diagnosis. Both of our patients had a family history on further questioning and despite their Portuguese descent; the rare isolated dystonic presentation misdirected the attention toward isolated focal dystonia. Therefore, a detailed family history and careful neurologic examination paying attention to any clues is invaluable, even in cases of what appears to be a typical torticollis.

\section{AUTHOR CONTRIBUTIONS}

Drafting/revising the manuscript for content, including medical writing for content: Jihad A. Muglan, Suresh Menon, Mandar S. Jog. Study concept or design: Jihad A. Muglan, Suresh Menon, Mandar S. Jog. Analysis or interpretation of data: Jihad A. Muglan, Suresh Menon, Mandar S. Jog. Administrative, technical, or material support: Jihad A. Muglan, Suresh Menon, Mandar S. Jog. Study supervision or coordination: Jihad A. Muglan, Suresh Menon, Mandar S. Jog.

\section{ACKNOWLEDGMENT}

The authors thank the patients for their participation in this study.

\section{STUDY FUNDING}

No targeted funding reported.

\section{DISCLOSURE}

J. Muglan has been funded by the Saudi Ministry of Health for a fellowship in movement disorders. S. Menon is a recipient of the McDonald Fellowship from the Multiple Sclerosis International Federation (MSIF). He has received travel awards/scholarships to present at conferences from the Consortium of MS Centers (CMSC), Western Pacific endMS Regional Research and Training Centre, MS Society of Canada, and European Committee for the Treatment and Research in Multiple Sclerosis (ECTRIMS). He has received the Biogen MS Clinical and Research Fellowship award and has served on the advisory board of a Genzyme patient support program workshop. M. Jog receives speaker and consultant honoraria from Merz Pharmaceuticals, Allergan, Novartis, Teva Pharmaceuticals, and AbbVie. Dr. Jog also receives peer-reviewed research grants from Canadian Institutes for Health Research, Academic Medical Organization of Southwestern Ontario, Parkinson Society Canada, Ontario Brain Institute, and MITACS. Go to Neurology.org for full disclosures.

\section{REFERENCES}

1. Lima L, Coutinho P. Clinical criteria for diagnosis of Machado-Joseph disease: report of a non-Azorena Portuguese family. Neurology 1980;30:319-322.

2. Hagenah JM, Zühlke C, Hellenbroich Y, Heide W, Klein C. Focal dystonia as a presenting sign of spinocerebellar ataxia 17. Mov Disord 2004;19:217-220.

3. Coutinho P, Andrade C. Autosomal dominant system degeneration in Portuguese families of the Azores Islands: a new genetic disorder involving cerebellar, pyramidal, extrapyramidal and spinal cord motor functions. Neurology 1978;28:703-709.

4. Suite ND, Sequeiros J, McKhann GM. Machado-Joseph disease in a Sicilian-American family. J Neurogenet 1986; 3:177-182.

5. Sakai T, Kawakami H. Machado-Joseph disease: a proposal of spastic paraplegic subtype. Neurology 1996;46: 846-847.

6. Subramony SH, Filla A. Autosomal dominant spinocerebellar ataxias ad infinitum? Neurology 2001;56:287-289.

7. Lang AE, Rogaeva EA, Tsuda T, Hutterer J, St GeorgeHyslop P. Homozygous inheritance of the MachadoJoseph disease gene. Ann Neurol 1994;36:443-447.

8. Rosenberg RN. Machado-Joseph disease: an autosomal dominant motor system degeneration. Mov Disord 1992;7:193-203.

9. Münchau A, Dressler D, Bhatia KP, Vogel P, Zühlke C. Machado-Joseph disease presenting as severe generalized dystonia in a German patient. J Neurol 1999;246: 840-842.

10. van Gaalen J, Giunti P, van de Warrenburg BP. Movement disorders in spinocerebellar ataxias. Mov Disord 2011;26:792-800. 


\section{Neurology}

\section{Pearls \& Oy-sters: Spinocerebellar ataxia type 3 presenting with cervical dystonia without ataxia}

Jihad A. Muglan, Suresh Menon and Mandar S. Jog

Neurology 2016;86; e1-e3

DOI 10.1212/WNL.0000000000002232

This information is current as of December 28, 2015

\section{Updated Information \&} Services

Supplementary Material

\section{References}

Subspecialty Collections

Permissions \& Licensing

\section{Reprints}

including high resolution figures, can be found at: http://n.neurology.org/content/86/1/e1.full

Supplementary material can be found at: http://n.neurology.org/content/suppl/2015/12/26/WNL.0000000000002 232.DC1

This article cites 10 articles, 3 of which you can access for free at: http://n.neurology.org/content/86/1/e1.full\#ref-list-1

This article, along with others on similar topics, appears in the following collection(s):

Dystonia

http://n.neurology.org/cgi/collection/dystonia Gait disorders/ataxia

http://n.neurology.org/cgi/collection/gait_disorders_ataxia

Information about reproducing this article in parts (figures,tables) or in its entirety can be found online at:

http://www.neurology.org/about/about_the_journal\#permissions

Information about ordering reprints can be found online: http://n.neurology.org/subscribers/advertise

Neurology ${ }^{\circledR}$ is the official journal of the American Academy of Neurology. Published continuously since 1951, it is now a weekly with 48 issues per year. Copyright () 2015 American Academy of Neurology. All rights reserved. Print ISSN: 0028-3878. Online ISSN: 1526-632X.

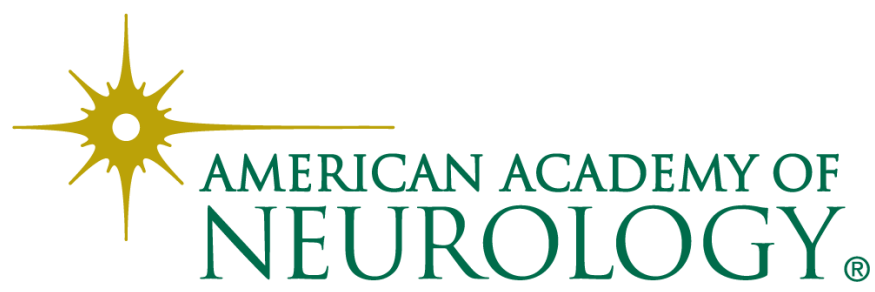

